Pediat. Res. 2: 187-192 (1968)

Amino acids aminogram

developmental biochemistry

cord blood nutrition

\title{
The Free Amino Acids of Serum During Development of M. Mulatta I. During the First Year of Life
}

\author{
G.R. KERR ${ }^{[27]}$ \\ Department of Pediatrics and the Wisconsin Regional Primate Research Center, \\ University of Wisconsin, Madison, Wisconsin, USA
}

\begin{abstract}
Extract
The serum levels of free amino acids have been investigated during the first year of postnatal life in the rhesus monkey ( $M$. mulatta). Samples of umbilical vein blood were obtained following normal full-term pregnancies. Infant monkeys were fed Similac ${ }^{\circledR}$, a proprietary milk formulation with constant amino acid composition, at four-hour intervals throughout the first year of life. Blood samples were obtained at 2 weeks and at 1, 3, 6, 9 and 12 months of age, and the serum analyzed for all free amino acids.

A wide range of values was evident for each amino acid at each age studied (table I). When all values obtained for each amino acid during the entire first year were analyzed, however, it was apparent that taurine, lysine, and 3-methyl-histidine were significantly elevated, and serine, tyrosine, and leucine were significantly reduced in the umbilical vein samples. By the end of the first month of life, values for all amino acids were within the normal range for adolescent and nonpregnant adult animals; further significant changes in amino acid levels did not occur during the remainder of the year of study.
\end{abstract}

\section{Speculation}

The nutritional correlates of growth and development in most laboratory animals are sufficiently different from those in the human to question their use in studies related to human nutrition. This study demonstrates that the patterns of change in the free amino acids of serum in the infant rhesus monkey are generally comparable to those observed in the human infant, and indicates that this species may be a suitable experimental counterpart for investigations of protein and amino acid metabolism which cannot be performed in children.

\section{Introduction}

The synthesis of all protein molecules depends upon the availability of adequate amounts of the composite amino acids. Free amino acids are maintained at higher levels in the intracellular space than in plasma $[14,15]$, and Ghristensen and StREIGHer have reported a positive correlation between the growth rate of an organ and the ability of its cells to incorporate amino acids [2]. Elevated extracellular levels of amino acids would thus lead to their maximum availability for the intracellular synthesis of new proteins [2, 19], and changes in the serum levels of amino acids might be anticipated during periods of rapid growth.

In order to study the relation between the state of nutrition and changes in the circulating free amino 
acids, it is first necessary to define those changes which occur normally during the various stages of development. As part of a series of studies involving nutritional disturbances during fetal life and infancy in a laboratory primate, this communication reports the changes in the levels of free amino acids of serum which occur normally during the first year of postnatal life in the rhesus monkey.

\section{Materials and Methods}

M. mulatta were kept in individual cages and maintained under standard conditions of light, temperature, and humidity. The date of conception was established for all pregnancies [7]. Eight pregnant females were fed a chow diet ${ }^{1}$ supplemented with fruit and vitamins. Immediately following spontaneous vaginal delivery, venous blood samples were obtained from the umbilical cord of the infant. In two newborns, umbilical cord blood could not be obtained and samples of peripheral blood were drawn from the femoral vein within five minutes of birth.

A second group of 15 normal infants were studied during the first year of extrauterine life. They were separated from their mothers within eight hours after spontaneous vaginal delivery and placed in individual, heated cages. During the first 24 hours they were fed a $10 \%$ glucose solution; during the second day this was supplemented by an equal volume of Similac ${ }^{\circledR}$, a proprietary milk formulation ${ }^{2}$. After 48 hours of age, and for the duration of the study, all animals were fed full-strength Similac ${ }^{\circledR}$ at four-hour intervals throughout the day and night. This milk preparation, supplemented with vitamins after the third day of life ${ }^{3}$, and seasonal fruit after 45 days of age, constituted the total nutrient intake. The volume of milk ingested, and increases in length, weight and head circumference were

${ }^{1}$ Purina Monkey Chow ${ }^{\circledR}$, Ralston Purina Co., St. Louis, Missouri.

${ }^{2}$ Similac ${ }^{\circledR}$, Ross Laboratories, Columbus, Ohio. Prepared at a dilution of $132 \mathrm{~g}$ Similac powder per liter of formula. The amino acid composition, expressed as $\mathrm{mg} / 100 \mathrm{ml}$ of the reconstituted milk, is as follows (data kindly provided by the manufacturer):

$\begin{array}{lrlr}\text { Histidine } & 40 & \text { Cystine } & 16 \\ \text { Leucine } & 180 & \text { Aspartic Acid } & 82 \\ \text { Methionine } & 44 & \text { Proline } & 124 \\ \text { Threonine } & 77 & \text { Valine } & 115 \\ \text { Arginine } & 63 & \text { Alanine } & 38 \\ \text { Isoleucine } & 107 & \text { Glutamic Acid } & 337 \\ \text { Lysine } & 130 & \text { Serine } & 79 \\ \text { Phenylalanine } & 87 & \text { Glycine } & 6 \\ \text { Tryptophan } & 25 & \text { Tyrosine } & 94 \\ \text { 3 Paladac } & { }^{\circledR}, \text { Parke, Davis \& Co., Detroit, Michigan. }\end{array}$

recorded. When possible, venous blood samples were obtained at exactly 2 weeks, and at 1, 3,6,9 and 12 months of age. Each blood sample was obtained four hours after a normal dietary intake, allowed to stand at $5^{\circ}$ for two hours, then centrifuged at 2,000 rpm for 20 minutes at $5^{\circ}$. The serum was separated and stored at $-20^{\circ}$ until analyzed. The free amino acid content of serum was determined by the GERRITSEN $e t$ al. modification [4] of the method of Spackman et al. [21] using the Beckman/Spinco amino acid analzyer.

Values for tryptophan and cystine will not be reported because of their instability during storage [3] and because of specific difficulties involved in the measurement of free, and protein-bound, tryptophan [4]. A decrease in glutamine and an increase in glutamic acid have also been noted coincident to prolonged storage of plasma samples [3]; although glutamine gives rise to compounds other than glutamic acid, the sum of both determinations will be presented. The chromatographic peak for aspartic acid was occasionally superimposed upon the peak for threonine, preventing in such cases the evaluation of both amino acids.

Student's $t$ test was used to assess the significance of differences $(\mathrm{p}<0.01)$ when umbilical cord levels were compared with those at 2 weeks, 1 month, or 1 year of age. Changes during the entire first year of life were analyzed by use of the Newman-Kuels multiple range test [24], which considers all values for each amino acid before indicating significant deviations from the series of measurements. Significance for this data was defined at a level of $\mathrm{p}<0.05$.

\section{Results}

Comparison of the free amino acid levels in the fullterm newborn and year-old infant monkeys showed that in the cord blood samples, levels of taurine, alanine, lysine, and 3-methyl-histidine were significantly increased, while those of serine and tyrosine were significantly decreased (fig. 1). During the first month of life, taurine, lysine and 3-methyl-histidine showed a significant fall. Histidine also showed a significant, but less striking, reduction (fig. 2). Serine and tyrosine, which were low in the cord samples, and phenylalanine, leucine and isoleucine showed significant increases during the same period of time (fig.3). Values for aspartic acid and threonine could not be defined at two weeks of age because their chromatographic peaks were superimposed, but all other amino acids did not show significant changes during the first month of life.

By one year of age, the levels of free amino acids of serum in the rhesus monkey have reached adult levels, and the values in animals fed Similac ${ }^{\circledR}$ are not signifi- 
The free amino acids of serum during development of $M$. mulatta. I. During the first year... 189

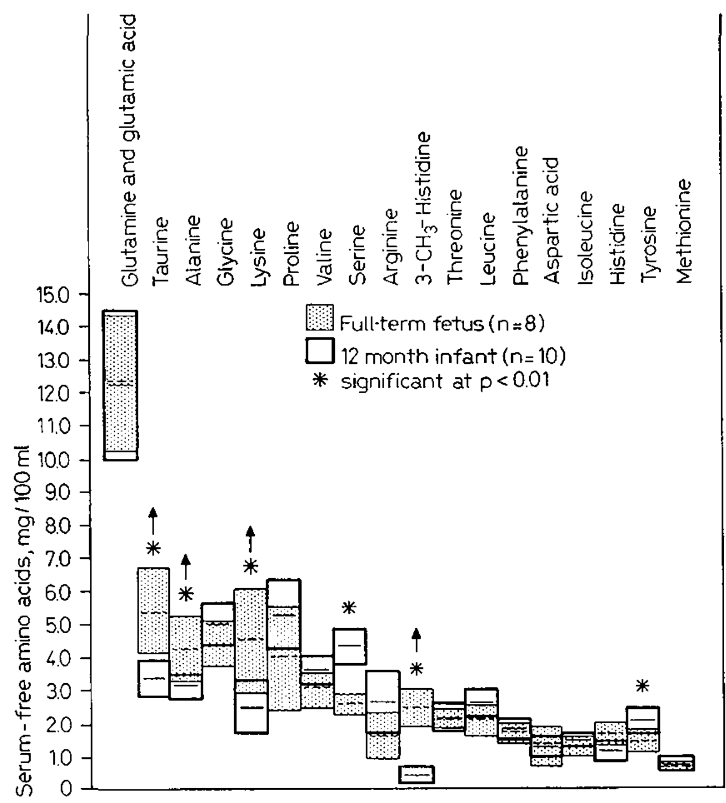

cantly different from those in animals fed commercial monkey chow. During the first year of life, a wide range of normal values was evident at all ages studied. Changes in mean values usually proved nonsignificant however, when evaluated by the Newman-Kuels test. Analysis of all values for each amino acid by this method indicated that significant differences $(\mathrm{p}<0.05)$ were found only in the umbilical vein samples; taurine, lysine and 3-methyl-histidine were higher, and serine, tyrosine and leucine were lower in the cord blood than in all other samples analyzed during the entire first year of life. The other amino acids did not show significant changes (table I).

Fig. 1. Serum levels of free amino acids in eight fullterm newborn and ten 12-month infant rhesus monkeys. Blocks represent mean values \pm 1 SD. Asterisks indicate significant differences and arrows indicate amino acids which are significantly higher in the cord samples $(t$ test, $\mathrm{p}<0.01)$.

Table $I$. Changes in the level of free amino acids of serum during the first year of extrauterine life in $M$. mulatta. Figures indicate the mean value $\pm 1 \mathrm{SD}$. Figures in parentheses indicate number of animals studied at each age. Asterisks indicate values significantly different from all other values for each amino acid during the first year of life (Newman-Kuels multiple range test, $\mathrm{p}<0.05$ ).

\begin{tabular}{|c|c|c|c|c|c|c|c|}
\hline Amino acids & $\begin{array}{l}\text { Cord } \\
(8)\end{array}$ & $\begin{array}{l}2 \text { weeks } \\
(5)\end{array}$ & $\begin{array}{l}1 \text { month } \\
(6)\end{array}$ & $\begin{array}{l}3 \text { months } \\
\text { (7) }\end{array}$ & $\begin{array}{l}6 \text { months } \\
(10)\end{array}$ & $\begin{array}{l}9 \text { months } \\
\text { (10) }\end{array}$ & $\begin{array}{l}12 \text { months } \\
\text { (10) }\end{array}$ \\
\hline Histidine & $1.72 \pm 0.35$ & $1.06 \pm 0.25$ & $1.44 \pm 0.17$ & $1.28 \pm 0.78$ & $1.32 \pm 0.44$ & $1.00 \pm 0.28$ & $1.26 \pm 0.42$ \\
\hline Phenylalanine & $1.68 \pm 0.28$ & $2.32 \pm 0.62$ & $2.29 \pm 0.37$ & $2.36 \pm 0.65$ & $1.77 \pm 0.33$ & $1.80 \pm 0.45$ & $1.87 \pm 0.33$ \\
\hline Lysine & $4.46 \pm 1.62 *$ & $1.74 \pm 0.71$ & $2.27 \pm 1.02$ & $2.37 \pm 1.90$ & $3.22 \pm 1.54$ & $2.26 \pm 0.85$ & $2.51 \pm 0.82$ \\
\hline Tyrosine & $1.46 \pm 0.33^{*}$ & $3.24 \pm 0.85$ & $2.65 \pm 1.22$ & $2.67 \pm 0.72$ & $2.24 \pm 0.94$ & $1.92 \pm 0.50$ & $2.09 \pm 0.44$ \\
\hline Leucine & $2.03 \pm 0.48 *$ & $2.63 \pm 0.66$ & $3.32 \pm 0.79$ & $3.31 \pm 0.54$ & $2.42 \pm 0.27$ & $2.36 \pm 0.75$ & $2.65 \pm 0.44$ \\
\hline Isoleucine & $1.27 \pm 0.20$ & $1.63 \pm 0.33$ & $1.91 \pm 0.41$ & $1.89 \pm 0.38$ & $1.37 \pm 0.20$ & $1.44 \pm 0.51$ & $1.54 \pm 0.23$ \\
\hline Taurine & $5.38 \pm 1.33^{*}$ & $3.62 \pm 1.35$ & $3.17 \pm 1.06$ & $3.28 \pm 0.73$ & $3.27 \pm 0.95$ & $3.74 \pm 1.26$ & $3.37 \pm 0.58$ \\
\hline Serine & $2.52 \pm 0.30^{*}$ & $4.41 \pm 0.91$ & $3.54 \pm 1.02$ & $4.73 \pm 0.84$ & $3.83 \pm 0.65$ & $3.84 \pm 0.95$ & $4.40 \pm 0.58$ \\
\hline Methionine & $0.72 \pm 0.12$ & $0.92 \pm 0.56$ & $1.04 \pm 0.44$ & $1.00 \pm 0.33$ & $0.84 \pm 0.06$ & $0.73 \pm 0.26$ & $0.81 \pm 0.20$ \\
\hline Arginine & $1.57 \pm 0.65$ & $1.53 \pm 0.55$ & $2.36 \pm 0.31$ & $2.29 \pm 1.41$ & $3.38 \pm 1.39$ & $2.05 \pm 0.95$ & $2.62 \pm 1.02$ \\
\hline \\
\hline glutamic acid & $12.32 \pm 2.11]$ & $11.19 \pm 3.28$ & $12.67 \pm 2.30$ & $11.16 \pm 2.13$ & $10.48 \pm 2.34$ & $10.32 \pm 2.96$ & $12.27 \pm 2.27$ \\
\hline Alanine & $4.26 \pm 1.04$ & $3.17 \pm 1.08$ & $3.15 \pm 0.28$ & $3.29 \pm 0.56$ & $2.73 \pm 0.85$ & $2.89 \pm 0.81$ & $3.16 \pm 0.40$ \\
\hline Glycine & $4.39 \pm 0.64$ & $4.11 \pm 0.73$ & $4.85 \pm 1.16$ & $4.95 \pm 0.20$ & $5.01 \pm 1.01$ & $4.97 \pm 1.43$ & $5.02 \pm 0.67$ \\
\hline 3-Methyl-histidine & $2.44 \pm 0.59 *$ & $0.33 \pm 0.23$ & $0.64 \pm 0.40$ & $0.20 \pm 0.17$ & $0.36 \pm 0.22$ & $0.31 \pm 0.13$ & $0.41 \pm 0.29$ \\
\hline Valine & $2.94 \pm 0.58$ & $3.31 \pm 0.82$ & $3.99 \pm 0.81$ & $4.30 \pm 1.43$ & $3.52 \pm 0.61$ & $3.19 \pm 1.08$ & $3.59 \pm 0.51$ \\
\hline Proline & $3.98 \pm 1.61$ & $4.94 \pm 1.26$ & $5.44 \pm 1.40$ & $5.17 \pm 1.11$ & $5.23 \pm 1.00$ & $4.87 \pm 0.87$ & $5.36 \pm 1.11$ \\
\hline Aspartic acid & $1.28 \pm 0.60$ & - & $1.90 \pm 0.37$ & $1.19 \pm 0.04$ & $1.10 \pm 0.42$ & $1.08 \pm 0.35$ & $1.21 \pm 0.30$ \\
\hline Threonine & $2.05 \pm 0.31$ & - & $2.64 \pm 0.91$ & $2.69 \pm 0.06$ & $2.03 \pm 0.75$ & $1.86 \pm 0.63$ & $2.12 \pm 0.44$ \\
\hline
\end{tabular}




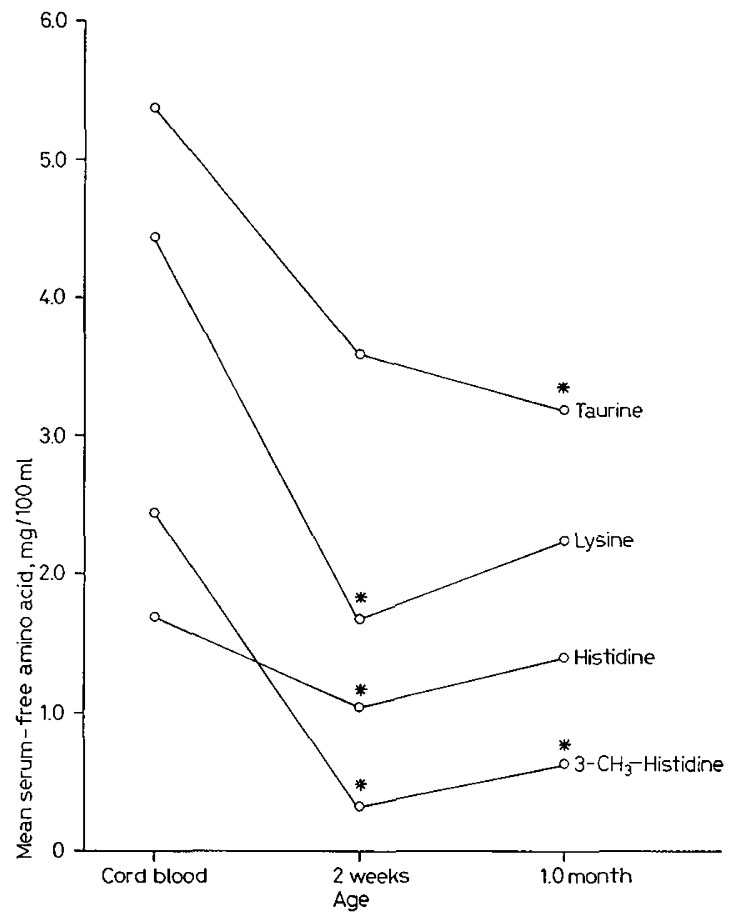

Fig. 2. Serum levels of free amino acids which decrease during the first month of extrauterine life in $M$. mulatta. Circles indicate mean values at each age. Asterisks indicate a significant reduction from the cord value ( $t$ test, $\mathrm{p}<0.01)$.

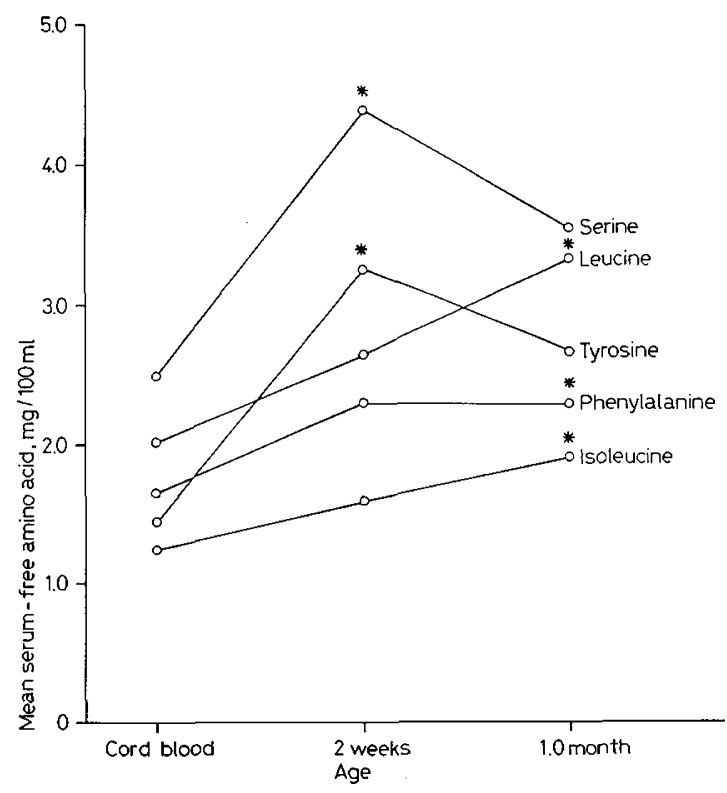

Discussion

The circulating amino acids are primarily important as they reflect and contribute to the larger pool of intracellular amino acids. They may, however, provide evidence of nutritional disturbances or the presence of congenital or acquired abnormalities of amino acid metabolism [6, 22, 23]. Investigations by LiGHTENstein [10], Schreier [16], Serini et al. [18], and GhaDIMI and PEcora [5a] have indicated that the levels of circulating amino acids are frequently elevated in premature infants. In the full-term human infant, however, levels of most amino acids are not significantly increased over those found in adults. The recent report of LINDBLAD and BALDESTEN [11] indicated that although the total value of all amino acids studied was higher in the cord blood of human infants than in nonpregnant women, only taurine, lysine, alanine, phenylalanine and glutamic acid showed significant increases. Dickinson et al. [3] and GHAdim and Pegora [5a] also indicated that only a few amino acids of cord blood, most notably taurine, lysine, glutamine, and threonine, were elevated over adult values. The present study indicated that, with the exception of taurine, lysine, alanine and 3-methyl-histidine, amino acids in umbilical vein blood of full-term infant rhesus monkeys were not significantly elevated over the levels in adolescent or nonpregnant adult animals. It is apparent, therefore, that in both human and subhuman primates, values for most amino acids are within the adult range at the time of full-term birth.

A wide range of normal values has been reported during infancy in the human $[5 b, 16,20]$, but several reports have indicated that significant changes may occur in plasma levels of a few amino acids during the first days or weeks of postnatal life. GHADIMI and PEcora [5b], Mathews and Partington [12], LA Du et al. [9], and Menkes and Avery [13] reported that plasma levels of tyrosine often became elevated shortly after birth; in premature infants, values up to $20 \mathrm{mg} \%$ were occasionally observed. LA Du et al. [9], Menkes and AVERy [13], and BERRY and LeonARD [1] reported that plasma phenylalanine levels were also frequently clevated during the postnatal period. A significant rise in tyrosine levels in serum was evident during the first weeks of extrauterine life in rhesus monkeys and was accentuated by the low value in umbilical cord blood. A postnatal increase in levels of phenylalanine in serum

Fig. 3. Serum levels of free amino acids which increase during the first month of extrauterine life in $M$. mulatta. Circles indicate mean values at each age. Asterisks indicate a significant increase from the cord value $(t$ test, $\mathrm{p}<0.01$ ). 
The free amino acids of serum during development of $M$. mulatta. I. During the first year... 191

also occurred but was not significant when considered with all other measurements obtained during the first year. KRETCHMER [8], has noted that the activities of enzymes responsible for the metabolism of tyrosine and phenylalanine are reduced during fetal and perinatal life, and Scriver has recently cautioned against overinterpretation of the resultant transient elevation of these amino acids [17].

Human newborns have low plasma levels of the branched-chain amino acids, leucine, isoleucine and valine [3, 5a], and BERRY and LeONARD [1] reported that the levels rose following initiation of feeding. Leucine and isoleucine demonstrated a rise after birth in newborn monkeys, but the rise was only significant for leucine and was primarily due to low umbilical cord values. A significant increase in serine also occurred during the first month of life in the monkey and was similarly due to reduced levels in umbilical cord blood.

Ghadimi and Pecora [5 b] noted decreases in taurine, lysine and threonine values during the first 10 days of life in human infants, and Dickinson et al. [3] and Schreier [16] also reported postnatal decreases in taurine and lysine. For methodological reasons, threonine values during the postnatal period could not be defined in the present study, but significant decreases were noted for both taurine and lysine. The change was due to a reduction of the elevated levels in umbilical cord blood and produced values comparable to those found in older control animals.

In general, therefore, the postnatal changes observed in individual circulating free amino acids in the macaque infant are similar in direction to those reported in the human neonate, and where significant changes occur, they are usually seen in both species. It is apparent that the postnatal changes in amino acid levels in the monkey result in normal adult values, with umbilical cord values presumably reflecting a difference between fetal and postnatal pathways of amino acid metabolism.

The values reported for several amino acids in this study are significantly higher than those established for human infants $[5 a, b, 11,16]$. Part of this discrepancy may be due to methodology; GERRITSEN et al. reported that their ultracentrifugation modification [4] of the method of SPACKMan, Stein and Moore [21] resulted in higher recoveries for several amino acids than were reported after either picric acid or sulfosalicilic acid deproteinization. The possibility that the higher levels reported in this study represent 'leakage' of amino acids from hematologic elements [20] must also be considered. Whether these changes reflect true species differences or procedural and methodologic differences, cannot be defined at the present time. Despite these differences, however, these data suggest that studies relating the effects of excesses or deficien- cies of dietary protein and amino acids, when performed in this subhuman primate, may aid in defining the changes in intermediary metabolism as well as in growth and development which occur, but are difficult to fully evaluate, in states of human malnutrition.

\section{Summary}

Changes in the free amino acids of serum have been studied during the first year of extrauterine life in the rhesus monkey. A wide range of normal values was apparent and it was necessary to consider all values for each amino acid in order to establish the significance of the changes. Taurine, lysine and 3-methyl-histidine were significantly elevated, and serine, tyrosine and leucine were significantly reduced in umbilical venous serum in comparison with values characteristic of the older animal. By the end of the first month of postnatal life, the serum levels of these amino acids had reached the levels found in older control animals and further significant changes did not occur. The umbilical cord level and all subsequent values for all other free amino acids were not different from those in nonpregnant adults.

\section{References and $\mathcal{N o t e s}$}

1. Berry, H.K. and Leonard, G.S.: Plasma amino acids in full-term infants. Amer. J. clin. Nutr. 19: 99 (1966).

2. Ghristensen, H.N. and Streicher, J. A. : Association between rapid growth and elevated cell concentrations of amino acids. J. biol. Chem. 175: 95 (1948).

3. Dickinson, J. G.; Rosenblum, H. and Hamilton, P.B.: Ion exchange chromatography of the free amino acids in the plasma of the newborn infant. Pediatrics 36: 2 (1965).

4. Gerritsen, T.; Rehberg, M.L. and Waisman, H.A.: On the determination of free amino acids in serum. Analyt. Biochem. 11: 460 (1965).

5. Gradimi, H. and Pecora, P.: Free amino acids of cord plasma as compared with maternal plasma during pregnancy. Pediatrics 33: 500 (1964a). Plasma amino acids after birth. Pediatrics 34: 182 (1964b).

6. Holt, L.E., Jr. and SNyderman, S. E.: Anomalies of amino acid metabolism; in Mammalian protein metabolism (ed. Munro, H.N. and Axlison, J. B.), vol.2, p.321 (Academic Press, New York 1964).

7. Jacobson, H.N. and Winde, W.F.: Observations on mating, gestation, birth and postnatal development of Macaca mulatta. Biol. Neonat. (Basel) 2: 105 (1960). 
8. KRETCHMER, N.: Enzymatic patterns during development. An approach to a biochemical definition of immaturity. Pediatrics 23: 606 (1959).

9. La Du, B. N.; Howell, R. R.; Michael, P.J. and SOBER, E.K.: Quantitative micromethod for the determination of phenylalanine and tyrosine in blood and its application in the diagnosis of phenylketonuria in infants. Pediatrics 31: 39 (1963).

10. Lrahtenstein, A.: Untersuchungen an Nabelschnurblut bei Frühgeborenen und ausgetragenen Kindern mit besonderer Berücksichtigung der Ảminosäuren. Z. Kinderheilk. 51: 748 (1931).

11. Lindblad, B.S. and Baldesten, A.: The normal venous plasma free amino acid levels of non-pregnant women and of mother and child during delivery. Acta paediat. (Uppsala) 56: 37 (1967).

12. Mathews, J. and Partington, M.W.: The plasma tyrosine levels of premature babies. Arch. Dis. Childh. 39: 371 (1964).

13. Menkes, J. and Avery, M. E.: The metabolism of phenylalanine and tyrosine in the premature infant. Bull.Johns Hopk. Hosp. 113: 301 (1963).

14. Roberts, E. and Simonsen, D.G.: Free amino acids in animal tissue; in Amino acid pools (ed. Holden, J.T.), p. 284 (Elsevier, New York 1962).

15. Scharf, R. and Wool, I. G.: Concentration of amino acids in rat muscle and plasma. Nature (Lond.) 202: 603 (1964).

16. SchreIER, K. : The behavior of amino acids in body fluids during development and growth: Physiology and pathology; in Amino acid pools (ed. Holden, J.T.), p. 263 (Elsevier, New York 1962).

17. ScRIver, G. R.: Diagnosis and treatment.: Interpreting the positive screening test in the newborn infant. Pediatrics 39: 764 (1967).

18. Sereni, F.; MaNamara,H.; Shibuya, M.; KretchMER, N. and BARNETT, H.L.: Concentration in plasma and rate of urinary excretion of amino acids in premature infants. Pediatrics 15: 575 (1955).

19. Van Slyke, D.D. and Meyer, G. M.: The fate of protein digestion products in the body. III. The absorption of amino acids from the blood by the tissues. J. biol. Chem. 16: 197 (1913).

20. Soupart, P.: Free amino acids of blood and urine in the human; in Amino acid pools (ed. Holden, J.T.), p. 220 (Elsevier, New York 1962).

21. Spackman, D.H.; Stein, W.H. and Moore, S.: Automatic recording apparatus for use in the chromatography of amino acids. Analyt. Chem. 30: 1190 (1958).

22. Warsman, H.A.: Some newer inborn errors of metabolism. Pediat. Clin. N. Amer. 13: 469 (1966).

23. Waisman, H.A. and KerR, G.R.: Amino acid and protein metabolism in the developing fetus and the newborn infant. Pediat. Clin. N.Amer. 12: 551 (1965).

24. WINER, B. J.: Statistical principles in experimental design (McGraw-Hill, New York 1962).

25. The technical assistance of Mssrs. JAmEs A. CAmpBeLl and Guenther R. Scheffler is gratefully acknowledged.

26. Supported by grant FR-00167 from the National Institutes of Health to the Wisconsin Regional Primate Research Center.

27. Requests for reprints should be addressed to: George R. Kerr, M.D., Department of Pediatrics, University of Wisconsin, Madison, Wis. 53706 (USA). 